Abstract G95(P) Table 1 Responses from regional survey

\begin{tabular}{|l|l|l|l|l|}
\hline & $\begin{array}{l}\text { Observe in hospital } \\
\text { without another } \\
\text { dose of } \\
\text { dexamethasone }\end{array}$ & $\begin{array}{l}\text { Administer a 2nd } \\
\text { dose of } \\
\text { dexamethasone in } \\
\text { hospital and observe }\end{array}$ & $\begin{array}{l}\text { Discharge home } \\
\text { with a dose of } \\
\text { dexamethasone }\end{array}$ & $\begin{array}{l}\text { Discharge home } \\
\text { without a dose of } \\
\text { dexamethasone }\end{array}$ \\
\hline $\begin{array}{l}12 \text { hours after a } \\
\text { dose of } \\
\text { dexamethasone for } \\
\text { croup, a patient } \\
\text { has no symptoms } \\
\text { at rest but } \\
\text { symptoms on } \\
\text { exertion. Which of } \\
\text { the following would } \\
\text { you opt for? }\end{array}$ & Total =25 (22\%) & Total =23(21\%) & Total =37 (33\%) & Total =27 (24\%) \\
\hline
\end{tabular}

croup. We completed an audit to review the use of dexamethasone in children with croup.

Method Inpatient notes of 50 children admitted between 2010 and 2011 were reviewed at a district general hospital. To gauge the readmission rate, a comparative notes review was performed for attendances at the Emergency Department of a local tertiary paediatric centre (150 attendances, June-November 2014).

Results Figure 1 shows results at the district general hospital

Half of the children who required readmission had the same croup score on their first admission and their second, implying that readmission was necessary due to lack of clinical improvement. At the tertiary centre, 90\% (135) patients received a dose of dexamethasone on their first presentation and 10\% (15) children re-attended.

With 1 in 10 patients being readmitted despite one dose of dexamethasone, we conducted a regional survey of paediatricians in our deanery to assess baseline practice for multi-dose dexamethasone. The survey contained a hypothetical case scenario of a child with croup (stridor and chest wall retraction at rest) who received a dose of dexamethasone. At $12 \mathrm{~h}$ the patient improved with no symptoms at rest but symptoms on exertion. Respondents were given four management options, as shown in Table 1. A total of 112 responses were received, 44\% from consultants.

The results demonstrate a wide variation in practice. $23 \%$ of respondents stated that their choice was based on trust guidelines, whereas $77 \%$ stated it was personal practice.

Conclusion The high readmission rate, variation in practice and lack of evidence for administering a second dose of dexamethasone in croup suggest this is a topic that would benefit from a research project.

\section{G96(P) OPTIMISING FACIAL IMAGING FOR TRAUMA IN A PAEDIATRIC EMERGENCY DEPARTMENT (ED)}

${ }^{1} \mathrm{JC}$ Chapman, ${ }^{2} \mathrm{E}$ Petridou, ${ }^{3} \mathrm{~S}$ Hartshorn, ${ }^{2} \mathrm{~K}$ Johnson. ${ }^{1}$ General Paediatrics/Paediatric Intensive Care Unit, Royal Stoke University Hospital, Stoke-on-Trent, UK; ${ }^{2}$ Radiology Department, Birmingham Children's Hospital, Birmingham, UK; ${ }^{3}$ Emergency Department, Birmingham Children's Hopital, Birmingham, UK

\subsection{6/archdischild-2015-308599.95}

Aims In the context of trauma, plain facial X-rays do not represent the gold standard imaging modality, as many patients with equivocal findings will require further imaging with facial CT views. The aim of this project was to review the use of facial $\mathrm{X}$-rays of patients seen in a paediatric ED following trauma, to ascertain the degree of correlation between clinical signs and radiological findings.

Methods Retrospective review. All facial X-rays performed within the ED over a 1 year period (09/2012-09/2013) were identified from the hospital PACS system. Clinical details were obtained from the ED notes and compared with the X-ray report from a consultant radiologist.

Results See Figure 1 below.

Conclusions The vast majority of facial X-rays performed in our ED showed no evidence of fracture. A negative X-ray may be falsely reassuring as, in some cases, clinical suspicion of bony injury was high, but no further investigation/referral was made. In other cases, a facial CT was performed despite a negative facial X-ray. Therefore, in general, facial X-rays and their interpretation by ED clinicians do not appear to make a significant difference to the subsequent clinical management of patients. If suspicion of fracture is high then CT would be a better imaging modality, as where suspicion remains high an equivocal plain X-ray result would not confidently exclude facial bone fracture.

On the basis of this we have developed a new clinical guideline which stratifies patients into 3 management paths according to clinical signs and symptoms:

\begin{tabular}{lll}
\hline Low Risk & Medium Risk & High Risk \\
\hline No imaging & ED clinic follow up in 2-3 days & \\
Patient & Facial X-ray (with rapid radiology & \\
discharged with advice & reporting) if clinical concern persists & Facial CT \\
\hline
\end{tabular}

Our intention is to reduce the number of unnecessary facial $\mathrm{X}$-rays, and practice will be re-audited one year postimplementation.

\section{G97(P) AUDIT OF SAFEGUARDING OF CHILDREN PRESENTING WITH DOG BITES TO THE EMERGENCY DEPARTMENT}

TJ van Hasselt, R Bowman, M Sajeel. Emergency Department, Good Hope Hospital, Birmingham, UK

\subsection{6/archdischild-2015-308599.96}

Aims Recently there has been much media coverage of dog attacks on children. NICE guidelines for management of dog bites recommend that inadequate supervision should prompt consideration of child neglect. 